\title{
Faculty and Student Online Experiences Amidst the COVID-19 Pandemic: A Descriptive Study (Part 1)
}

Shelley Cobbett

Dalhousie University, shelley.cobbett@dal.ca

Patricia A. Hansen-Ketchum

St. Francis Xavier University, phketchu@stfx.ca

Nadine Ezzeddine

Dalhousie University, nadine.ezzeddine@dal.ca

Willena I. Nemeth

Cape Breton University, willena_nemeth@cbu.ca

Debbie Brennick

University College of Cape Breton, debbie_brennick@cbu.ca

Follow this and additional works at: https://qane-afi.casn.ca/journal

Part of the Nursing Commons, and the Scholarship of Teaching and Learning Commons

\section{Recommended Citation}

Cobbett, Shelley; Hansen-Ketchum, Patricia A.; Ezzeddine, Nadine; Nemeth, Willena I.; and Brennick, Debbie (2022) "Faculty and Student Online Experiences Amidst the COVID-19 Pandemic: A Descriptive Study (Part 1)," Quality Advancement in Nursing Education - Avancées en formation infirmière: Vol. 8: Iss. 1, Article 4.

DOI: https://doi.org/10.17483/2368-6669.1317

This Article is brought to you for free and open access by Quality Advancement in Nursing Education - Avancées en formation infirmière. It has been accepted for inclusion in Quality Advancement in Nursing Education - Avancées en formation infirmière by an authorized editor of Quality Advancement in Nursing Education - Avancées en formation infirmière. 
Faculty and Student Online Experiences Amidst the COVID-19 Pandemic: A Descriptive Study (Part 1)

\section{Cover Page Footnote}

Sincere gratitude is extended to all of the students and faculty who responded to our survey during a time when we were "totally" online. Nous exprimons notre sincère gratitude à toutes les étudiantes et professeures qui ont répondu à notre sondage lors d'une période où nous étions « entièrement » en ligne. 


\section{Introduction}

Postsecondary institutions in a Canadian Eastern province closed campuses and moved online with the declaration of a provincial state of emergency in March 2020 related to the SARSCoV-2 pandemic. Three university schools of nursing that offer the bachelor of science in nursing $(\mathrm{BScN})$ program on a tri-semester basis joined together shortly thereafter to investigate student and faculty experiences of learning and teaching online. There was a need to fill knowledge gaps in the literature to better understand online experiences, as well as the barriers and facilitators to teaching and learning during a pandemic.

With the suspension of clinical placement for student learners in most clinical practice areas, schools rapidly worked to rearrange course offerings to front load theory in the spring and summer semesters in an online environment and shift clinical practice to the fall semester, as well as adding virtual clinical simulation to help meet student learning outcomes. The current study investigates student and faculty experiences during this swift pedagogical shift to immersion in the online environment during a global pandemic. This article provides an overview of the quantitative findings.

\section{Background/Literature}

A pre-study literature review yielded few results beyond editorials, student and faculty reflections, and blog postings in relation to COVID-19. Rose (2020, "How COVID-19 Affects the Preclerkship Learning Environment" section) provided a viewpoint on the transition of theory courses to the online environment in medical education, including small group work and examinations, and stressed that the shift from work "to home results in isolation, ...increased use of email, and struggles with establishing boundaries between work and home." In an editorial, Bauchner and Sharfstein (2020) called for suspension of medical education in the United States for the fall of 2020 and enrollment of those students in an online service program for public health; others (Harvey, 2020; Mahase, 2020) advocated for early registration of medical students and newly educated doctors.

The ever-changing and uncertain landscape of the COVID-19 pandemic forced educational institutions to be fluid with contingency plans for courses and competency development, each with a differing approach depending on local context, student, and program needs. Educators became innovative and leveraged technology to rise to the challenge of maintaining quality education online (Liang et al., 2020). Evaluation of the learning and teaching that has occurred during the pandemic is critical to harnessing new ideas and best practices in education for the future.

Before beginning data collection, the team was unable to locate any published research studies related to the nursing student or faculty experience of learning and teaching in the online environment during the COVID-19 pandemic.

\section{Methods}

Using a descriptive survey design, the team emailed to participants a study information sheet and an invitation to complete an online survey related to their experience of learning or teaching in the fully online environment. Two data collection instruments were used: Faculty Survey of Online Teaching Amidst the COVID-19 Pandemic and the Student Survey of Online Learning Amidst the COVID-19 Pandemic. Face validity was confirmed by the research team in consultation with the Centre for Teaching and Learning. Qualitative data from open-ended questions were analyzed for resulting themes from each group and quantitative data provided 
demographic statistics to describe the sample and compare student perceptions of their learning experience with the faculty perceptions of their teaching experience. Ethical approval for this study was received from all three university ethics review boards and informed consent was obtained from study participants.

The aim of this multi-site research was to understand the experiences of students and faculty when rapidly shifting to an online learning and teaching environment in three nursing education programs during a global pandemic.

The following research questions were investigated:

1. What was the experience of nursing students and faculty in a Canadian province learning and teaching in the fully online environment during the COVID-19 pandemic?

2. Is there a relationship between the students' and the faculty members' perception of the effectiveness, engagement, and comfort in the online learning/teaching experience?

\section{Results}

The results below are limited to the quantitative data collected. The quantitative findings are organized by faculty and student data. The discussion section provides a comparison among the data.

\section{Faculty Results}

The Faculty Online Learning Amidst the COVID-19 Pandemic Survey was administered online between July 24 and September 7, 2020, using the Opinio software platform with 51 faculty invited to participate $(74.5 \%$ response rate $[N=38]) ; 30$ participants completed the entire survey.

\section{Sample}

The faculty sample consisted of faculty from all three universities. Almost half of the sample $(47 \%, n=14)$ has taught at the postsecondary level for greater than 15 years, followed by $23 \%(n=7)$ for 1 to 5 years, $17 \%(n=5)$ for 11 to 15 years, $10 \%(n=3)$ for 6 to 10 years, and $3 \%$ $(n=1)$ for less than 1 year. Forty-three percent $(n=13)$ of the sample resided in a rural area, $50 \%$ $(n=15)$ reported living in an urban area, and 7\% $(n=2)$ resided outside the study province during the summer 2020 semester. The majority $(53 \%, n=16)$ had dependants living with them.

Before March 2020, about 53\% $(n=16)$ of faculty reported that they had previously taught fully online courses. During the spring/summer session, about $40 \%(n=12)$ of faculty offered fully online courses that were asynchronous with optional synchronous sessions, and $23 \%(n=7)$ offered their courses with all asynchronous requirements. Mandatory synchronous courses were required by $33 \%(n=10)$ of faculty, and $3 \%(n=1)$ offered both mandatory and optional synchronous sessions.

\section{Teaching Online}

Over three-quarters of faculty reported using a laptop for online teaching $(80 \%, n=24)$ with $17 \%(n=5)$ reporting use of a desktop and 3\% $(n=1)$ using a tablet. Accessible or adaptive technologies for online teaching were reported as a requirement for about $13 \%(n=4)$ of faculty. On a scale of 1 (poor) to 5 (excellent), internet connectivity was reported as very good or excellent by $88 \%(n=22)$ of faculty (mean, 4.28 ; median, 4$)$. 
The top three most used educational technologies as indicated by the faculty were the use of an online learning management system (LMS), live video connections (e.g., Microsoft Teams, Zoom) and video recordings. Table 1 displays the various online educational technologies that faculty reported using.

\section{Table 1}

Educational Technology Use

\begin{tabular}{|c|c|c|}
\hline Technology used & $N$ & $\%$ of total $N$ \\
\hline $\begin{array}{l}\text { Online learning management system (e.g., Moodle, } \\
\text { Brightspace) }\end{array}$ & 26 & 16.4 \\
\hline Live video (e.g., Microsoft Teams, Zoom) & 23 & 14.5 \\
\hline Video recordings & 17 & 10.7 \\
\hline Textbook publisher resources & 17 & 10.7 \\
\hline Discussion board & 15 & 9.4 \\
\hline Virtual simulation & 14 & 8.8 \\
\hline Audio recordings & 12 & 7.5 \\
\hline Evolve & 10 & 6.3 \\
\hline BB Collaborate & 7 & 4.4 \\
\hline Polling, quizzing & 6 & 3.8 \\
\hline Media resources & 5 & 3.1 \\
\hline OER (open educational resources) & 3 & 1.9 \\
\hline Other (Video notes, instant messaging, breakout rooms) & 4 & 2.5 \\
\hline $\begin{array}{l}\text { Total (note: } N \text { not equal to } 30 \text { as some used more than } \\
\text { one educational technology) }\end{array}$ & 159 & $100 \%$ \\
\hline
\end{tabular}

Faculty self-rating of comfort using online educational technologies before and after March 2020 revealed differences. Before the spring/summer semester, only 15\% $(n=4)$ of faculty reported being extremely comfortable; after this semester, $42 \%(n=11)$ indicated they were extremely comfortable using online educational technologies. In fact, after the semester, $89 \%(n=$ 23 ) of the faculty participants indicated they were comfortable or extremely comfortable with the use of online technology, compared to before this semester, with 56\% $(n=15)$ of faculty reporting this same comfort level. Although comfort levels increased post-summer semester, a chi-square test of independence showed no significant association between comfort level pre- and postsummer semester $\left(\chi^{2}(2, N=53)=5.333, p=.07\right)$.

With a rapid shift to online teaching and learning, over half of the faculty that responded $(58 \%, n=15)$ reported that their workload for the spring/summer semester increased by more than $50 \%, 27 \%(n=7)$ indicated their workload increased but by less than $50 \%, 12 \%(n=3)$ indicated 
no change in workload, and about $4 \%(n=1)$ indicated their workload decreased. Four participants did not respond to this question.

\section{Support}

Regarding perceived pedagogical support from their institution for online teaching, about $15 \%(n=4)$ of the faculty participants indicated excellent support, 39\% $(n=10)$ indicated good support, and about $8 \%(n=2)$ indicated poor support. On a scale of 1 (no support) to 5 (excellent support), the mean was 3.64 and the median was 4 . In relation to perceived technological support from their institution for online teaching, 38\% $(n=10)$ reported excellent support, $46 \%(n=12)$ reported good support, with no responses indicating "no support" (mean, 4.15; median, 4). Faculty perception of support for exclusive online teaching from their own school or department revealed differences. About 20\% ( $n=5)$ of faculty indicated no or poor school or departmental support, and $27 \%(n=7)$ indicated excellent support (mean, 3.58; median, 4).

\section{Work/Life Balance}

Participants were asked to rate their ability to maintain a work/life balance while working remotely from home. More than $80 \%(n=21)$ of faculty participants indicated that they were unable to balance (rating of 1) or barely able to balance (rating of 2) their work/life ratio. Only $15 \%(n=4)$ of faculty indicated they had little or no problem achieving an appropriate work/life balance while teaching remotely during the pandemic.

\section{Faculty Perception of Student Experience}

Faculty were asked several questions about their perception of how students viewed the online learning and teaching in the spring-summer semester. When asked to rate their students perceived online learning experience during the spring-summer semester, about $40 \%(n=15)$ indicated that students perceived their online learning to be effective or extremely effective. Conversely, about $8 \%(n=2)$ indicated that they thought their students perceived the online learning experience as an ineffective method of learning. On a 1 (not effective) to 5 (extremely effective) Likert scale, the mean was 3.67 (median 4).

Regarding faculty perception of students' preference for synchronous online learning, only one faculty respondent indicated that students highly preferred synchronous learning, and one faculty indicated that this type of learning was not at all preferred by their students. Eight faculty participants $(21 \%)$ perceived students to be neutral, and another 8 faculty $(21 \%)$ considered students to prefer synchronous learning. Conversely, about $23 \%(n=6)$ of faculty indicated that they thought students preferred or highly preferred asynchronous online learning. Almost twothirds of faculty $(62 \%, n=16)$ reported that the better learning environment for students is a combination of both synchronous and asynchronous teaching and learning activities. Approximately $15 \%(n=4)$ of faculty felt that synchronous requirements provide a better learning experience for students whereas $12 \%(n=3)$ indicated that asynchronous requirements provide a better learning experience for students. Twelve percent $(n=3)$ of faculty did not reply to this question.

Faculty were asked to rate their perception of the overall effectiveness of the springsummer semester teaching and learning based upon their own definition of "teaching effectiveness" on a Likert scale of 1 (not at all effective) to 5 (extremely effective). Over half of respondents $(58 \%, n=15)$ reported a 4 or a 5 on this question, indicating that faculty felt that the spring-summer semester was overall effective from a teaching and learning perspective. There 
were no responses indicating "not at all effective," with 8\% $(n=2)$ choosing 2 and 27\% $(n=7)$ choosing 3 , with four respondents not replying to this question.

\section{Perceived Student Engagement}

Faculty were asked to rate the level of student engagement in their course using various online educational technologies. Using a 5-point Likert scale from 1 (not at all engaged) to 5 (extremely engaged), data were collected related to educational technologies used when teaching remotely during the spring/summer semester. Table 2 displays the resulting data.

Table 2

Perceived Level of Student Engagement by Faculty Related to Education Technologies

\begin{tabular}{|c|c|c|c|c|c|c|c|c|c|}
\hline Technology & $\begin{array}{c}1 \text { (not at } \\
\text { all } \\
\text { engaged) }\end{array}$ & 2 & 3 & 4 & $\begin{array}{c}5 \\
\text { (extremely } \\
\text { engaged) }\end{array}$ & N/A & $\begin{array}{c}\text { NO } \\
\text { Answer }\end{array}$ & Mean & Median \\
\hline $\begin{array}{l}\text { Virtual } \\
\text { simulation }\end{array}$ & 0 & 0 & 2 & 5 & 6 & 10 & 7 & 4.31 & 4 \\
\hline Polling & 0 & 1 & 0 & 2 & 2 & 17 & 8 & 4.00 & 4 \\
\hline Quizzing & 0 & 0 & 4 & 5 & 4 & 9 & 8 & 4.00 & 4 \\
\hline OER & 1 & 0 & 0 & 5 & 3 & 12 & 9 & 4.00 & 4 \\
\hline LMS & 0 & 0 & 7 & 10 & 6 & 3 & 4 & 3.96 & 4 \\
\hline $\begin{array}{l}\text { Media } \\
\text { resources }\end{array}$ & 0 & 0 & 3 & 5 & 2 & 11 & 9 & 3.90 & 4 \\
\hline $\begin{array}{l}\text { Video } \\
\text { recordings }\end{array}$ & 0 & 0 & 6 & 8 & 3 & 6 & 7 & 3.82 & 4 \\
\hline Evolve & 0 & 0 & 4 & 6 & 1 & 11 & 8 & 3.73 & 4 \\
\hline $\begin{array}{l}\text { Discussion } \\
\quad \text { board }\end{array}$ & 1 & 1 & 4 & 6 & 4 & 7 & 7 & 3.69 & 4 \\
\hline $\begin{array}{c}\text { Live video } \\
\text { (Microsoft } \\
\text { Teams, Zoom) }\end{array}$ & 1 & 1 & 9 & 7 & 4 & 4 & 4 & 3.55 & 3.5 \\
\hline $\begin{array}{l}\text { Textbook } \\
\text { publisher } \\
\text { resources }\end{array}$ & 0 & 1 & 5 & 4 & 0 & 12 & 8 & 3.30 & 3 \\
\hline $\begin{array}{c}\text { BB } \\
\text { Collaborate }\end{array}$ & 1 & 0 & 4 & 3 & 0 & 16 & 6 & 3.13 & 3 \\
\hline WiKi tool & 0 & 1 & 0 & 1 & 0 & 18 & 10 & 3.00 & 3 \\
\hline $\begin{array}{l}\text { Audio } \\
\text { recordings }\end{array}$ & 1 & 1 & 5 & 5 & 1 & 9 & 8 & 2.92 & 3 \\
\hline
\end{tabular}




\section{Student Results}

The Student Online Learning Amidst the COVID-19 Pandemic Survey was administered online between July 24 and September 7, 2020, using the Opinio software platform, with 631 students invited to participate (31\% response rate $[N=195])$; 193 participants completed the entire survey.

\section{Sample}

The student sample consisted of students from all three universities. Fifty-eight percent of the sample $(n=114)$ resided in urban areas, $28 \%$ resided in rural areas $(n=54), 5 \%(n=10)$ resided outside the province during the summer 2020 semester, and 5\% $(n=17)$ did not respond to this question. The majority $(68 \%, n=132)$ of the students did not have dependants living with them, $21 \%(n=41)$ were living with dependants, and 20 participants did not respond. For program of study, $55 \%(n=107)$ of students had entered university directly from high school or had no previous university experience, $28 \%(n=55)$ were advanced standing/accelerated program students, $7 \%(n=13)$ were in the LPN-BScN stream, and $11 \%(n=22)$ of students did not respond.

Sixty-one percent of the student participants worked during the spring-summer semester either full time $(15 \%, n=29)$, part time $(22 \%, n=43)$, or casual $(24 \%, n=47)$. About $27 \%$ of the students $(n=53)$ reported not working during this time, and $12 \%$ of respondents $(n=23)$ did not reply to this question. Approximately $41 \%(n=79)$ of the students worked in health care-related positions during this period.

\section{Learning Online}

The sample was almost evenly divided related to prior experience with fully online courses: $46 \%$ of the students $(n=90)$ reported having previously taken a fully online course, $46 \%$ reported they had not $(n=89)$, and 8\% $(n=16)$ did not respond. About 7\% $(n=12)$ of students indicated that they had a learning accommodation before the declaration of the pandemic.

Eighty-eight percent $(n=171)$ of the student participants mainly used a laptop for online learning, $2 \%(n=4)$ reported using a desktop, $1.5 \%(n=3)$ reported using a tablet, and $0.5 \%(n$ $=1$ ) used a cellphone. On a scale of 1 (poor) to 5 (excellent), internet connectivity was reported as very good or excellent by $52 \%(n=101)$ of the students whereas about $13 \%(n=26)$ indicated somewhat poor or poor internet connectivity (mean, 3.62; median, 4).

Student self-rating of comfort using online educational technologies before and after March 2020 revealed differences. Before the spring-summer semester, only 14\% $(n=27)$ of students reported being extremely comfortable using online educational technologies whereas after this semester, $20 \%(n=39)$ indicated they were extremely comfortable. About $21 \%(n=40)$ of students indicated they were not at all comfortable or somewhat uncomfortable with using online educational technologies before this session, reducing to $13 \%(n=25)$ after the completion of the summer semester. A chi-square test of independence was performed to examine the relationship between comfort level pre- and post-summer session and found the relationship between these variables as significant $\left(\chi^{2}(2, N=358)=8.14, p=.017\right)$ indicating that students were more comfortable with online technologies post-summer semester.

Forty-five percent of students rated their experience of obtaining required textbooks and readings as very good $(n=53)$ or excellent $(n=35)$, with about $20 \%$ indicating their experience was fair $(n=26)$ or poor $(n=12)$. 


\section{Student Engagement}

On a scale of 1 (not at all engaged) to 5 (extremely engaged), 31\% $(n=60)$ of the students indicated that they were not at all engaged $(n=19)$ or minimally engaged $(n=41)$ in their courses, and $33 \%(n=64)$ indicated they were extremely engaged $(n=24)$ or somewhat engaged $(n=40)$. With a median of 3 and a mean of 3.05, less than half of the sample reported course engagement.

Students were asked to rate the level of engagement in their course using various online educational technologies. Data were collected using a 5-point Likert scale from 1 (not at all engaged) to 5 (extremely engaged) about the various educational technologies used when learning remotely during the spring-summer semester. Table 3 displays the results in order from highest to lowest engagement. Approximately $38 \%$ of students indicated that the online educational technologies that were used provided very good $(n=44)$ or excellent $(n=14)$ support for their learning while $11 \%$ of students indicated these technologies provided fair $(n=24)$ or poor $(n=14)$ support for their learning.

\section{Table 3}

Self-Reported Level of Student Engagement in Education Technologies

\begin{tabular}{|c|c|c|c|c|c|c|c|c|c|c|}
\hline Technology & $\begin{array}{c}1 \\
\text { Not at } \\
\text { all } \\
\text { engaged }\end{array}$ & 2 & 3 & 4 & $\begin{array}{c}5 \\
\text { Extremely } \\
\text { engaged }\end{array}$ & N/A & $\begin{array}{c}\text { No } \\
\text { Answer }\end{array}$ & Mean & Median & $\begin{array}{l}\text { Faculty } \\
\text { ranking }\end{array}$ \\
\hline LMS & 5 & 19 & 37 & 34 & 57 & 1 & 42 & 3.78 & 4 & 5 \\
\hline Quizzing & 4 & 14 & 35 & 44 & 41 & 13 & 44 & 3.75 & 4 & 3 \\
\hline $\begin{array}{c}\text { Live video } \\
\text { (Microsoft } \\
\text { Teams, Zoom) }\end{array}$ & 9 & 20 & 33 & 37 & 50 & 4 & 42 & 3.66 & 4 & 10 \\
\hline Evolve & 9 & 19 & 32 & 30 & 35 & 28 & 42 & 3.50 & 4 & 8 \\
\hline $\begin{array}{l}\text { Virtual } \\
\text { simulation }\end{array}$ & 10 & 17 & 37 & 42 & 32 & 15 & 42 & 3.50 & 4 & 1 \\
\hline $\begin{array}{l}\text { Video } \\
\text { recordings }\end{array}$ & 16 & 21 & 44 & 36 & 24 & 12 & 42 & 3.20 & 3 & 7 \\
\hline Polling & 9 & 21 & 28 & 18 & 13 & 62 & 44 & 3.06 & 3 & 2 \\
\hline Media resources & 16 & 26 & 32 & 31 & 16 & 32 & 42 & 3.04 & 3 & 6 \\
\hline $\begin{array}{l}\text { Discussion } \\
\text { board }\end{array}$ & 23 & 34 & 26 & 32 & 23 & 13 & 44 & 2.99 & 3 & 9 \\
\hline $\begin{array}{l}\text { Audio } \\
\text { recordings }\end{array}$ & 26 & 35 & 37 & 24 & 15 & 16 & 42 & 2.76 & 3 & 14 \\
\hline BB Collaborate & 10 & 18 & 14 & 17 & 13 & 79 & 44 & 2.65 & 3 & 12 \\
\hline $\begin{array}{l}\text { Textbook } \\
\text { publisher } \\
\text { resources }\end{array}$ & 28 & 41 & 45 & 17 & 14 & 8 & 42 & 2.64 & 3 & 11 \\
\hline OER & 25 & 12 & 24 & 16 & 7 & 67 & 44 & 2.62 & 3 & 4 \\
\hline WiKi tool & 25 & 17 & 3 & 3 & 2 & 102 & 43 & 1.80 & 1 & 13 \\
\hline
\end{tabular}




\section{Student Preference}

Over half of the students $(52 \%, n=79)$ reported that they preferred synchronous learning online, and about $17 \%(n=26)$ of students indicated that this was not their preference. About half of the student participants $(49 \%, n=75)$ reported that they preferred asynchronous learning, and $31 \%(n=47)$ reported they did not prefer this type of learning.

Students were asked to rate their preference for learning via face-to-face learning, blended learning, and fully online learning. Over three-quarters of the students $(84 \%)$ totally preferred $(n$ $=103)$ or preferred $(n=25)$ face-to-face learning, and $7 \%$ did not prefer this type of learning. Almost half of the students totally preferred $(n=32)$ or preferred $(n=41)$ blended learning, and about $18 \%(n=39)$ did not prefer this learning modality. Interestingly, fully online learning was totally preferred $(n=11)$ and preferred $(n=15)$ by approximately $17 \%$ of respondents, with the majority of students $(68 \%, n=104)$ not preferring this type of learning. Table 4 details student responses to their preference for learning modality.

\section{Table 4}

Student Preference for Learning Modality

\begin{tabular}{cccccccccc} 
Modality & $\begin{array}{c}\mathbf{1} \text { (not at } \\
\text { all } \\
\text { preferred) }\end{array}$ & $\mathbf{2}$ & $\mathbf{3}$ & $\mathbf{4}$ & $\begin{array}{c}\mathbf{5} \text { (totally } \\
\text { preferred) }\end{array}$ & N/A & $\begin{array}{c}\text { No } \\
\text { Answer }\end{array}$ & Mean & Median \\
\hline $\begin{array}{c}\text { Face-to-face } \\
\text { learning }\end{array}$ & 3 & 7 & 14 & 25 & 103 & 1 & 42 & 4.43 & 5 \\
$\begin{array}{c}\text { Blended } \\
\text { learning }\end{array}$ & 12 & 15 & 52 & 41 & 32 & 1 & 42 & 3.43 & 3 \\
$\begin{array}{c}\text { Fully online } \\
\text { learning }\end{array}$ & 86 & 18 & 23 & 15 & 11 & 0 & 42 & 2.00 & 1 \\
\hline
\end{tabular}

\section{Course Outcomes}

In relation to students' reports of meeting their course learning outcomes, $72 \%(n=141)$ indicated that they met the outcomes, $6 \%(n=11)$ reported they did not meet the course outcomes, and $22 \%(n=43)$ did not respond. Just under half of respondents $(42 \%)$ indicated that the overall effectiveness of the spring-summer semester was not at all effective $(n=17)$ or not effective $(n=$ $47)$, and $28 \%$ indicated it was extremely effective $(n=13)$ or effective $(n=30)$. About one-quarter of the class reported a 3 to this question, indicating that they felt it was neither effective nor ineffective $(n=42)$.

\section{Communication}

Over $83 \%$ ( $n=127)$ of students who responded to this question indicated that they used online communication/collaboration tools, and 17\% $(n=26)$ indicated they did not use online communication. Examples of platforms used included Microsoft Teams, Zoom, FaceTime, Facebook, WhatsApp, BB Collaborate, Slack, Google docs, LMS discussion board, and email. 


\section{Mental Health and Support}

Forty-one percent of students indicated very good $(n=30)$ or excellent $(n=33)$ accessibility to peer support, with $32 \%$ indicating their access to this support as fair $(n=33)$ or poor $(n=15)$. Students were asked to rate their perception of their institution's support of various activities on a scale of 1 (no support) to 5 (excellent support). Table 5 displays the perceived support, from the most support to the least support. Students reported that they received the most support from their institution/school related to COVID-19 information (mean, 3.39; median, 3) and the least support related to student study supports (mean, 2.49; median, 2).

\section{Table 5}

Student Perceived Institutional Support

\begin{tabular}{|c|c|c|c|c|c|c|c|c|c|}
\hline SUPPORT & $\begin{array}{c}1 \text { (no } \\
\text { support) }\end{array}$ & 2 & 3 & 4 & $\begin{array}{c}5 \\
\text { (excellent } \\
\text { support) }\end{array}$ & N/A & $\begin{array}{c}\text { No } \\
\text { Answer }\end{array}$ & Mean & Median \\
\hline $\begin{array}{l}\text { COVID-19 } \\
\text { information }\end{array}$ & 14 & 18 & 48 & 40 & 33 & 0 & 42 & 3.39 & 3 \\
\hline $\begin{array}{l}\text { Library } \\
\text { resource } \\
\text { access }\end{array}$ & 8 & 34 & 40 & 36 & 25 & 10 & 42 & 3.25 & 3 \\
\hline $\begin{array}{l}\text { Course-related } \\
\text { information }\end{array}$ & 12 & 36 & 43 & 41 & 21 & 0 & 42 & 3.15 & 3 \\
\hline $\begin{array}{c}\text { University/ } \\
\text { school } \\
\text { updates, } \\
\text { decisions, and } \\
\text { events }\end{array}$ & 16 & 28 & 50 & 36 & 21 & 2 & 42 & 3.12 & 3 \\
\hline Technological & 14 & 39 & 48 & 28 & 12 & 12 & 42 & 2.89 & 3 \\
\hline $\begin{array}{l}\text { Student health } \\
\text { and well-being } \\
\text { resources }\end{array}$ & 25 & 33 & 45 & 27 & 14 & 9 & 42 & 2.81 & 3 \\
\hline $\begin{array}{l}\text { Student study } \\
\text { supports }\end{array}$ & 30 & 48 & 37 & 14 & 11 & 13 & 42 & 2.49 & 2 \\
\hline
\end{tabular}

\section{Faculty and Student Perceptual Differences}

There was a statistically significant difference between the faculty and students' perception of effectiveness of learning and teaching in the spring-summer semester $(t=3.59, d f=173, p=$ .0004 ) with faculty indicating teaching and learning effectiveness to be higher than the actual reported effectiveness as perceived by students.

The faculty perception of students' preference for synchronous and asynchronous learning versus the student preference for synchronous and asynchronous learning revealed statistically 
significant differences. Students' reported preference for synchronous learning was statistically higher than the faculty perception of student preference $\left(\chi^{2}[4, N=179]=9.868, p=.04\right)$. Conversely, students reported preference for asynchronous learning was statistically lower than the faculty perception of student preference $\left(\chi^{2}[4, N=173]=21.247, p=>.001\right)$.

The $t$-test results of student reported course engagement and faculty perceived student engagement revealed statistically significant differences with two online learning technologies: virtual simulation $(t=-2.11, d f=149, p=.04)$ and open educational resources (OERs) $(\mathrm{t}=-2.07$, $d f=91, p=.004)$. Faculty perceived that students were more engaged in virtual simulation and the use of OERs than the students reported as their actual engagement.

There were no statistically significant differences between faculty and students' perceptions in relation to perceived comfort in teaching and learning online pre- and post- summer semester $\left(\chi^{2}[3, N=317]=3.246, p=.36\right)$.

\section{Discussion}

Understanding the student experience of remote learning during the pandemic can help to inform faculty online pedagogy and mitigate identified stressors in efforts to support student success. Faculty competency in online pedagogical practices has been linked to learning satisfaction for both faculty and students (Konrad et al., 2021).

\section{Capacity Building for Online Learning}

About half of the students in the study had not previously taken a fully online course, which may have contributed to their satisfaction and comfort with their virtual learning experience during the pandemic. Previous experience with e-learning is associated with an overall higher level of satisfaction among students for learning during the pandemic (Alqahtani et al., 2021). Additional academic skills are necessary to be successful in courses in the virtual environment. Students require technological self-efficacy, self-directedness, time management skills, and strong communication skills (Zimmerman \& Kulikowich, 2016) and should be adaptable to various teaching styles when teaching and learning styles do not align with their preferences (Pryce-Miller $\&$ Serrant, 2019). The need for these skills to enhance success in the online learning environment may explain why over half of the students preferred synchronous online learning. It is important that faculty are aware of this preference as only one faculty member reported that students highly preferred synchronous learning. Asynchronous learning may have affected the students' perceived ability to succeed when an online course does not have any mandatory synchronous requirements (Murphy \& Stewart, 2017).

Over half of the faculty perceived the remote learning and teaching to be effective during this time, conflicting with about half of the students responding that the semester was not at all effective. However, almost all students reported meeting course learning outcomes. It may be that students view a pass in the course as equivalent to meeting all course learning outcomes. Similar results were found by Zheng and Zhu (2020) when studying online teaching during the pandemic for surgical nursing, reporting almost two-thirds of their sample indicated that the effectiveness of online teaching during the pandemic was inferior to face-to-face teaching.

The lack of perceived support by some students and faculty during this experience speaks to the ongoing need to improve pedagogical, institutional, technological, and peer support. Nursing faculty can collaborate with students to identify what types of supports would be most beneficial when learning remotely, and what would have helped them to be more engaged in their virtual 
learning. Similarly, faculty can debrief and analyze what would have been more helpful for faculty and students. When moving from the face-to-face environment to the virtual environment, social interaction in learning was minimized. The pedagogical shift abruptly caused by the COVID-19 pandemic reduced the students' possibility for social interactions in the learning process, thereby negatively affecting their learning and motivation (Langegård et al., 2021).

Christopher et al. (2020) provided guidance for the implementation of a strong, caring pedagogy during the pandemic, including humanizing the virtual classroom to include narrative and theory-guided pedagogical approaches-for example, creating safe online spaces for students to talk with faculty, peers, or professionals; being cognizant of the multiple demands that come with remote working/learning from home; and having students share their stories related to their current educational journey. Faculty understanding of remote instruction learning styles and appreciation for the individuality of each students' personal circumstances during the pandemic can increase student confidence and success. Gaffney et al. (2021) recommended that faculty identify those students at greater risk of experiencing difficulties during this time and support them to optimize their success.

\section{Technology Support}

Almost half of the students reported poor internet connectivity, which has a bearing on engagement and ability to complete course work. Faculty must bear this in mind when planning online learning activities that require a higher bandwidth, including audio and video recordings. Other authors have identified that internet access and web conferencing logistics during the pandemic have caused students difficulty with virtual simulations (Fogg et al., 2020; Koirala et al., 2020) and readiness for online learning (Oducado, 2021). Faculty did not have a similar experience with poor internet connectivity.

The importance of the LMS, or course website, cannot be overstressed. Students indicated that the LMS had the highest perceived engagement whereas the faculty ranked student engagement in the LMS fifth highest, a stark difference in faculty perception versus actual student experience. Knowing the importance of the LMS to student learning and engagement puts the onus on faculty to ensure that the LMS is clear, all-inclusive, and easy to navigate. It would behoove faculties to create and adopt a LMS template for all their courses to optimize student comfort in course site navigation.

\section{Engagement}

A glaring perceptual difference in relation to engagement occurred with virtual simulations (VS) in that faculty rated their perception of student engagement much higher than students ranked their actual engagement. Perhaps the perceptual difference was related to missing the social interaction in learning that occurs in face-to-face clinical simulations. Or maybe it was the lack of, or different, pre-brief and debriefing activities between face-to-face debriefs and virtual debriefs. When using VS in remote learning, it is important that the best simulation practices for virtual debriefing are used (Cheng et al., 2020). The format for virtual simulation activities may be altered in the online environment - for example, with an increased emphasis on building and maintaining psychological safety, and attention to minimizing cognitive load to maximize mental capacity (Cheng et al., 2020). The importance of ensuring they are done well should not be underestimated. Palancia Esposito and Sullivan (2020) provided an example of using virtual simulations, with students reporting that it engaged them, facilitated their learning, and enhanced their understanding by hearing and sharing differing perspectives. Wands et al. (2020) found that students engaged 
most when virtual simulations followed a consistent structure, were interactive, and contained visually engaging materials. Virtual clinical simulation, complete with prebriefing and debriefing requirements according to best practices, has been supported as an effective learning experience (Weston \& Zauche, 2020).

\section{Stress and Coping}

Fitzgerald and Konrad (2021) explored anxiety and stress in nursing students during the first few months of the COVID-19 pandemic and found that many students reported difficulty concentrating, anxiety, and concerns about self or family and friends contracting the virus. The most common stressors for students were academic requirements, with students reporting difficulty in meeting academic expectations because of the workload. They suggested ways to help students reduce their stress and anxiety by having them practise self-care and by providing a structured learning environment, detailed course schedules, open communication in a timely manner, and adaptable assignments when required using available resources. Students with financial, family, or emotional problems reported significantly higher stress levels because of the pandemic than did their peers who did not report these issues (Gallego-Gómez et al., 2020).

Most of the faculty participants indicated that they were not able to maintain a healthy work/life balance, defined as "the extent to which employees hold a favorable evaluation regarding their combination of work and non-work roles, arising from the belief that their emotional experiences, involvement, and effectiveness in work and non-work roles are commensurate with the value they attach to the roles" (Casper et al., 2018, p. 199). There is little empirical evidence available related to work/life balance among faculty, although discussions related to work/life balance among academics are recently gaining momentum (Pautz \& Vogel, 2020). The importance of maintaining a self-defined healthy work/life balance, during or post-pandemic, is extremely important to avoid faculty burnout, which can lead to decreased job satisfaction and lack of motivation (Pautz \& Vogel, 2020). During the sudden move to online learning caused by the pandemic, faculty indicated an exponential increase in their workload. Giménez-Espert et al. (2020) reported that a high workload is associated with low well-being and a high risk of health issues.

\section{Limitations}

Limitations to this study include the potential sampling bias that occurs when using a convenience sample, thereby limiting the generalizability of findings, as well as a potential response bias related to the nature of collecting self-reported data. During the data collection time, students and faculty were working and learning remotely, which may have affected their responses as they were still "living" in the experience that the research team was studying. Although the data are representative of the collective voice of almost 200 nursing students, the lower response rate $(31 \%)$ to the student survey may have influenced the results.

\section{Implications}

Perhaps the best pedagogical online practice is a mixture of both synchronous and asynchronous learning, with the understanding of individual student circumstances that may affect their ability to fully engage in synchronous learning. A viable option is to ensure that the synchronous learning opportunities are available to those who are unable to attend for personal reasons - for example, children/partner at home or employment commitments. The key is to strike 
the balance to engage students, make the learning available to all regardless of personal situations, and maintain a high-quality educational offering while supporting multiple learning styles.

\section{Conclusion}

The quantitative findings from this study aid in understanding the student experience of complete online learning during the pandemic and the faculty experience of teaching during the pandemic in three schools of nursing. The discussion addressed capacity building for online learning, the importance of technological support and reliable internet connections, faculty and student perceptual differences related to student engagement, and academic stressors and the inability to maintain a healthy work/life balance. The depth and breadth of the data did not allow for the presentation of the quantitative and qualitative findings in a single article because of space restrictions. The qualitative findings will be reported in a second article, discussing the three main themes that emerged from the data: learning and teaching (evaluation, environment), relationships (social isolation, virtual relations, communications), and mental health (academic shock, the "waiting" game, technology, resiliency, work/life balance). Nurse educators need to embrace the opportunities for new ways to deliver effective and efficient learning that were experienced during this shift to virtual learning. 


\section{References}

Alqahtani, N., Innab, A., \& Bahari, G. (2021). Virtual education during COVID-19: Exploring factors associated with e-learning satisfaction among Saudi nursing students. Nurse Educator, 46(2), E18-E22. https://doi.org/10.1097/NNE.0000000000000954

Bauchner, H., \& Sharfstein, J. (2020). A bold response to the COVID-19 pandemic: Medical students, national service, and public health. JAMA, 323(18), 1790-1791. https://doi.org/10.1001/jama.2020.6166

Casper, W., Vaziri, H., Wayne, J., DeHauw, S., \& Greenhaus, J. (2018). The jingle-jangle of work-nonwork balance: A comprehensive meta-analytic review of its meaning and measurement. Journal of Applied Psychology, 103(2), 182-214. https://doi.org/10.1037/apl0000259

Cheng, A., Kolbe, M., Grant, V., Eller, S., Hales, R., Symon, B., Griswold, S., \& Eppich, W. (2020). A practical guide to virtual debriefings: Communities of inquiry perspective. Advances in Simulation, 5, 18. https://doi.org/10.1186/s41077-020-00141-1

Christopher, R., de Tantillo, L., \& Watson, J. (2020). Academic caring pedagogy, presence, and Communitas in nursing education during the COVID-19 pandemic. Nursing Outlook, 68(6), 822-829. https://doi.org/10.1016/j.outlook.2020.08.006

Fitzgerald, A., \& Konrad, S. (2021). Transition in learning during COVID-19: Student nurse anxiety, stress, and resource support. Nursing Forum, 1-7. https://doi.org/10.1111/nuf.12547

Fogg, N., Wilson, C., Trinka, M., Campbell, R., Thomson, A., Merritt, L., Tietze, M., \& Prior, M. (2020). Transitioning from direct care to virtual clinical experiences during the COVID-19 pandemic. Journal of Professional Nursing, 36(6), 685-691. https://doi.org/10.1016/j.profnurs.2020.09.012

Gaffney, M. K., Chargualaf, K. A., \& Ghosh, S. (2021). COVID-19 Disruption of nursing education and the effects on students' academic and professional confidence. Nurse Educator, 46(2), 76-81. https://doi.org/10.1097/NNE.0000000000000986

Gallego-Gómez, J. I., Campillo-Cano, M., Carrión-Martínez, A., Balanza, S., RodríguezGonzález-Moro, M. T., Simonelli-Muñoz, A. J., \& Rivera-Caravaca, J. M. (2020). The COVID-19 pandemic and its impact on homebound nursing students. International Journal of Environmental Research and Public Health, 17(20), 7383. https://doi.org/10.3390/ijerph17207383

Giménez-Espert, M., Prado-Gasco, V., \& Soto-Rubio, A. (2020). Psychosocial risks, work engagement, and job satisfaction of nurses during COVID-19 pandemic. Frontiers in Public Health, 8, 566896. https://doi.org/10.3389/fpubh.2020.566896

Harvey, A. (2020). Covid-19: Medical students and FY1 doctors to be given early registration to help combat covid-19. BMJ (Clinical Research Ed.), 368, m1268. https://doi.org/10.1136/bmj.m1268

Koirala, D., Silwal, M., Gurung, S., Bhattarai, M., \& Kc, V. K. (2020). Perception towards online classes during COVID-19 among nursing students of a medical college of Kaski 
District, Nepal. Journal of Biomedical Research \& Environmental Sciences, 1(6), 249255. https://doi.org/10.37871/jbres1151

Konrad, S., Fitzgerald, A., \& Deckers, C. (2021). Nursing fundamentals - Supporting clinical competency online during the COVID-19 pandemic. Teaching \& Learning in Nursing, 16(1), 53-56. https://doi.org/10.1016/j.teln.2020.07.005

Langegård, U., Kiani, K., Nielsen, S. J., \& Svensson, P.-A. (2021). Nursing students’ experiences of a pedagogical transition from campus learning to distance learning using digital tools. BMC Nursing, 20(1), 1-10. https://doi.org/10.1186/s12912-021-00542-1

Liang, Z. C., Ooi, S. B. S., \& Wang, W. (2020). Pandemics and their impact on medical training: Lessons from Singapore. Academic Medicine: Journal of the Association of American Medical Colleges, 95(9), 1359-1361. https://doi.org/10.1097/ACM.0000000000003441

Mahase, E. (2020). Covid-19: Medical students to be employed by NHS as part of epidemic response. BMJ (Clinical Research Ed.), 368, m1156. https://doi.org/10.1136/bmj.m1156

Murphy, C. K., \& Stewart, J. C. (2017). On-campus students taking online courses: Factors associated with unsuccessful course completion. Internet High Education, 34, 1-9. https://doi.org/10.1016/j.iheduc.2017.03.001

Oducado, R. M. (2021). New normal in nursing education: Sophomore students' expectations of and readiness for online learning in the era of COVID-19 pandemic (SSRN Scholarly Paper ID 3765841). Social Science Research Network. https://papers.ssrn.com/abstract $=3765841$

Palancia Esposito, C., \& Sullivan, K. (2020). Maintaining clinical continuity through virtual simulation during the COVID-19 pandemic. Journal of Nursing Education, 59(9), 522525. https://doi.org/10.3928/01484834-20200817-09

Pautz, M., \& Vogel, M. (2020). Investigating faculty motivation and its connection to faculty work-life balance: Engaging public service motivation to explore faculty motivation. Journal of Public Affairs Education, 26(4), 437-457. https://doi.org/10.1080/15236803.2020.1776076

Pryce-Miller, M., \& Serrant, L. (2019). Students' perceptions of self-direction in pre-registration nurse education. Nurse Education in Practice, 40, 102626. https://doi.org/10.1016/j.nepr.2019.102626

Rose, S. (2020). Medical student education in the time of COVID-19. JAMA, 323(21), 21312132. https://doi.org/10.1001/jama.2020.5227

Wands, L., Geller, D. E., \& Hallman, M. (2020). Positive outcomes of rapid freeware implementation to replace baccalaureate student clinical experiences. Journal of Nursing Education, 59(12), 701-704. https://doi.org/10.3928/01484834-20201118-08

Weston, J., \& Zauche, L. H. (2020). Comparison of virtual simulation to clinical practice for prelicensure nursing students in pediatrics. Nurse Educator, https://doi.org/10.1097/NNE.0000000000000946

Zheng, T., \& Zhu, X. (2020). Comparing the effects of online teaching during the COVID-19 pandemic and traditional teaching in surgical nursing. BMC Nursing. https://doi.org/10.21203/rs.3.rs-108407/v1 
Quality Advancement in Nursing Education - Avancées en formation infirmière, Vol. 8, Iss. 1 [2022], Art. 4

Zimmerman, W., \& Kulikowich, J. (2016). Online learning self-efficacy in students with and without online learning experience. American Journal of Distance Education, 30(3), 180191. https://doi.org/10.1080/08923647.2016.1193801 